Distribución natural de restos óseos en la franja intermareal del sur de Tierra del Fuego: observaciones tafonómicas e implicancias arqueológicas

Daniela V. Alunni, Atilio F. Zangrando, Angélica M. Tivoli, Suray A. Pérez, Sayuri Kochi, María P. Martinoli, Martín M. Vázquez, Germán Pinto Vargas, María A. Gutiérrez

Relaciones, 46(2), e023, julio-diciembre 2021 ISSN 1852-1479 | https://doi.org/10.24215/18521479e023 https://revistas.unlp.edu.ar/relaciones

ISSN 0325-2221 (versión impresa)

Sociedad Argentina de Antropología (SAA)

Buenos Aires I Argentina

\title{
DISTRIBUCIÓN NATURAL DE RESTOS ÓSEOS EN LA FRANJA INTERMAREAL DEL SUR DE TIERRA DEL FUEGO: OBSERVACIONES TAFONÓMICAS E IMPLICANCIAS ARQUEOLÓGICAS
}

\author{
Daniela V. Alunni*, Atilio F. Zangrando ${ }^{* *}$, Angélica M. Tivoli ${ }^{* * *}$, Suray A. Pérez ${ }^{* * * *}$, \\ Sayuri Kochi ${ }^{* * * * *}$, María P. Martinoli ${ }^{* * * * * *}$, Martín M. Vázquez, ${ }^{* * * * * * *}$, \\ Germán Pinto Vargas ${ }^{* * * * * * * * *}$ y María A. Gutiérrez ${ }^{* * * * * * * * *}$
}

Fecha de recepción: 15 de enero de 2021

Fecha de aceptación: 9 de junio de 2021

\section{RESUMEN}

Se analiza el patrón de la distribución natural de huesos actuales en los distintos sectores de la franja costera de bahía Moat. Con este fin se busca evaluar los espacios donde existen ma-

\footnotetext{
* Centro Austral de Investigaciones Científicas (CADIC-CONICET).E-mail: alunni_d@yahoo.com.ar

** Centro Austral de Investigaciones Científicas (CADIC-CONICET). - Facultad de Filosofía y Letras, Universidad de Buenos Aires.E-mail: fzangrando@cadic-conicet.gob.ar; panchozan@yahoo.com.ar

**** Centro Austral de Investigaciones Científicas (CADIC-CONICET). E-mail: amtivoli@gmail.com **** Centro Austral de Investigaciones Científicas (CADIC-CONICET). E-mail: suryviaja@ gmail.com ***** Instituto de Geocronología y Geología Isotópica (INGEIS). Consejo Nacional de Investigaciones Científicas y Técnicas (CONICET), Universidad de Buenos Aires (UBA). Pabellón INGEIS. E-mail: kochisayuri@gmail.com

******* Centro Austral de Investigaciones Científicas (CADIC-CONICET).E-mail: mpmartinoli@ yahoo.com.ar ******* Centro Austral de Investigaciones Científicas (CADIC-CONICET). E-mail: vazquezmartin68@ gmail.com

******** Centro Austral de Investigaciones Científicas (CADIC-CONICET). E-mail: germanpv_11@yahoo. com.ar

${ }^{* * * * * * * * *}$ Instituto de Investigaciones Arqueológicas y Paleontológicas del Cuaternario Pampeano, Consejo Nacional de Investigaciones Científicas y Tecnológicas (INCUAPA-CONICET); Facultad de Ciencias Sociales, Universidad Nacional del Centro de la Provincia de Buenos Aires. E-mail: mgutierr@soc.unicen.edu.ar
} 
yores posibilidades de acumulación y dispersión de restos óseos y de generar expectativas sobre la integridad de los sitios arqueológicos. Asimismo, se evalúan las modificaciones naturales que se producen en la superficie cortical de los huesos. Los resultados muestran que la dinámica del intermareal actúa de manera disímil en la formación de los conjuntos óseos y que dichos procesos impactan en diferentes grados según la ubicación y la geoforma costera. Además, se identificaron distintas trayectorias tafonómicas para las aves y los mamíferos. Los resultados permiten predecir el grado de integridad de los sitios ubicados en los contextos ambientales aquí estudiados y constituyen herramientas valiosas para tomar decisiones en el marco de proyectos arqueológicos regionales.

Palabras clave: tafonomía actualista - dinámica costera - restos faunísticos - formación de sitio - bahía Moat

NATURAL DISTRIBUTION OF BONE REMAINS IN THE

INTERTIDAL ZONE FROM THE SOUTH OF TIERRA DEL FUEGO: TAPHONOMIC OBSERVATIONS AND ARCHAEOLOGICAL IMPLICATIONS

\section{ABSTRACT}

In this paper, the natural distribution pattern of modern bone remains in different parts of the Moat Bay coastal area is analyzed. The purpose of this analysis is to assess the areas with a higher probability of bone remains accumulation and dispersion, and to generate expectations about the integrity of archaeological sites. Additionally, the natural modifications that occur on the cortical surface of bones are evaluated. Results show that intertidal zone dynamics has a dissimilar effect in bone assemblage formation, and that these processes have different impact level depending on location and coastal landform type. Furthermore, different taphonomic trajectories for birds and mammals were identified. Results allow predicting the integrity level of the sites located in the environmental contexts under study and provide valuable decision-making tools for archaeological projects in this region.

Keywords: actualistic taphonomy - coastal dynamics - faunal remains - site formation Moat Bay

\section{INTRODUCCIÓN}

Los espacios intermareales de la costa sur de Tierra del Fuego contienen un amplio y diverso registro arqueológico que ha permitido conocer el desarrollo e historia evolutiva de los grupos humanos que habitaron la región (Orquera y Piana 1999; Zangrando 2009; Bjerck et al. 2016; entre otros). Sin embargo, el estudio de estas evidencias se enfrenta con desafíos metodológicos al hallarse en ambientes tafonómicamente activos, con elevado potencial de acumulación, pérdida, transporte y mezcla de materiales arqueológicos (Bayón y Politis 2014; Borrero 2014; Grosso et al. 2019). Esto tiene particular relevancia para comprender la formación de concheros, dado que estas estructuras están sujetas a una serie de procesos erosivos y sedimentarios que, combinados con el desarrollo de otros factores biológicos y geológicos (isostasia, tectónica, transgresiones marinas, etc.), plantean discusiones en diferentes escalas sobre la visibilidad y preservación del registro arqueológico costero (Orquera y Piana 1991; Borella y Favier Dubois 1994-95; Rick et al. 2006; Cruz et al. 2015; Zangrando 2018; Grosso et al. 2019; entre otros). Explorar los procesos que actúan en el ambiente intermareal también resulta necesario para el estudio de contextos pre-transgresivos distribuidos no solo bajo los sedimentos modernos en sectores próximos a la 
costa actual, sino también en zonas sumergidas debajo del nivel del mar (Zangrando et al. 2021).

Diversos estudios tafonómicos locales disponibles para la costa Atlántica de Tierra del Fuego y de Patagonia meridional observaron que los reiterados ciclos de erosión y cobertura por sedimentos producen hoyadas de deflación, remueven y depositan objetos y generan palimpsestos de materiales de diferentes períodos (Borella y Favier Dubois 1994-95; Borella 2004; Cruz 2008; Cruz et al. 2015; Muñoz et al. 2016). El contexto geográfico y ecológico de estos espacios propicia el desarrollo de estos procesos: el litoral es poco accidentado, con franjas de médanos a corta distancia del mar y declives levemente marcados; la vegetación está constituida por pastos y arbustos bajos. En cambio, en la costa sur de Tierra del Fuego la configuración del ambiente costero es distinta y presenta otros condicionantes para la acción del viento: las playas constituyen estrechas franjas de contacto entre la cordillera andina y el mar, son en su mayoría de gravas y guijarros, y se encuentran interrumpidas por tramos abruptos en afloramientos de till (depósitos de origen glaciario). El entorno pericostero comprende un denso bosque de Nothofagus, intercalado por superficies con extensiones variables de pastizales y turberas. Por lo tanto, a diferencia de la estepa patagónica, la presencia del cordón montañoso, el sustrato de las playas y la vegetación servirían como protección y resguardo del registro arqueológico contra el azote de los vientos. En este sentido, los patrones de acumulación y preservación podrían ser distintos a los observados en norte de Tierra del Fuego y Patagonia continental.

Estudios tafonómicos de base actualista iniciados recientemente en bahía Moat (Alunni et al. 2017: figura 1) permitieron dar cuenta de que el espacio intermareal presenta la mayor tasa de acumulación y diversidad taxonómica de restos óseos en comparación con otros sectores del paisaje. Estos mismos resultados indican que los huesos tienen distintos orígenes: desde elementos transportados por el mar hasta animales que mueren en la costa. Si se considera que la mayoría de los sitios arqueológicos se ubica sobre geoformas litorales y que la marea acumula gran cantidad de restos faunísticos, la potencial incorporación y mezcla de huesos naturalmente depositados y materiales arqueológicos puede ser elevada (Borrero 2014; Alunni et al. 2017). Se ha observado también que en bahía Moat la acción de las mareas produce la erosión de sitios arqueológicos, cuyos restos son removidos, desplazados y modificados por el mar.

Estas primeras observaciones mostraron la necesidad de ampliar los estudios tafonómicos a partir de registros más intensivos en el sector costero con el fin de profundizar nuestro conocimiento sobre los procesos que intervienen en la formación de los depósitos naturales y arqueológicos.

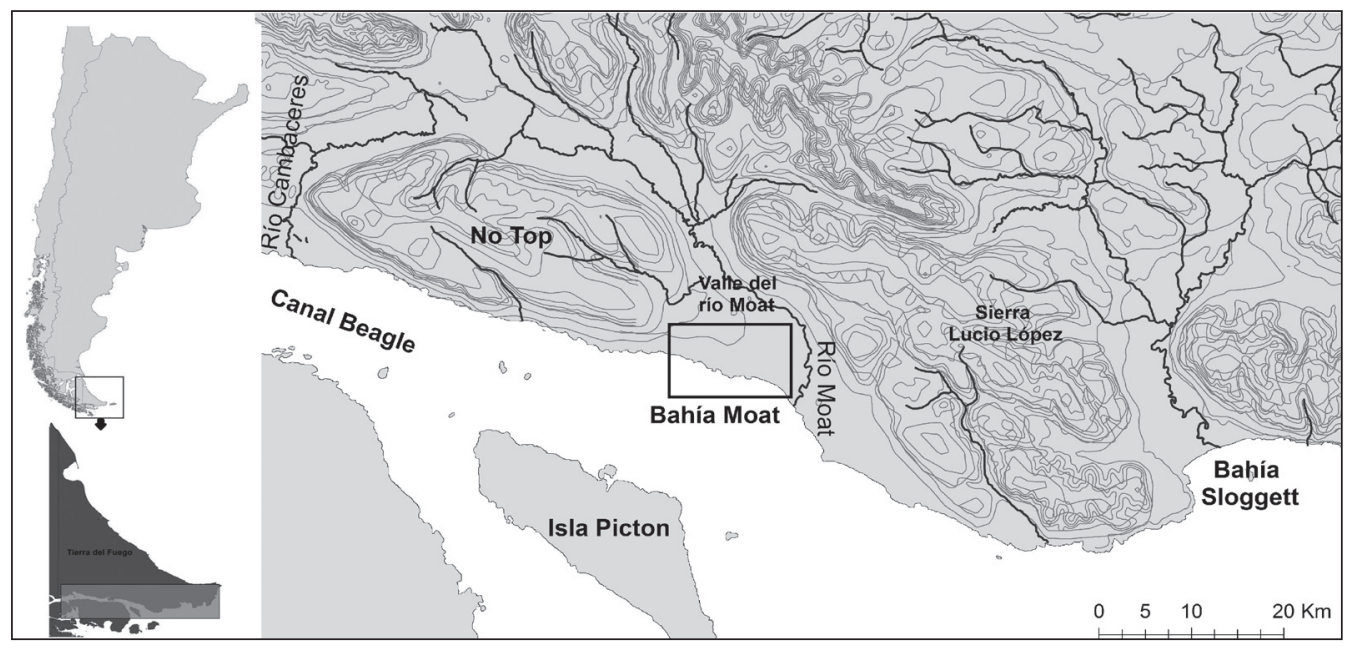

Figura 1. Mapa del área de estudio 
A continuación, presentamos los resultados obtenidos y analizamos el patrón de acumulación y dispersión de huesos entre los distintos sectores que conforman la franja costera de bahía Moat. Además, identificamos los espacios donde existen mayores posibilidades de alteración de sitios y de mezcla entre materiales arqueológicos y naturales. Esto implica analizar la ubicación y la distancia de los sitios arqueológicos identificados, ya sea cercanos o distantes de la costa, para evaluar los procesos involucrados. Asimismo, se pretende determinar las modificaciones naturales que se producen sobre los huesos de diversos taxones como consecuencia de la acción del mar, la atmósfera y la actividad carroñera, y evaluar la intensidad de estos procesos para las distintas especies faunísticas. Los resultados de este trabajo permitirán predecir el impacto que los procesos naturales generan sobre la preservación diferencial de los taxones representados en los conjuntos arqueológicos costeros.

\section{CARACTERÍSTICAS GENERALES DEL AMBIENTE}

La cuenca de Moat se ubica hacia el tramo centro-oriental de la costa sur de Tierra del Fuego (figura 1). El clima se clasifica como templado-frío oceánico, con una temperatura media anual de $5,3^{\circ} \mathrm{C}$ (Iturraspe y Schroeder 2015). Es un ambiente ventoso y húmedo, con valores mensuales de precipitación similares a lo largo de todo el año, entre 700 y $1.000 \mathrm{~mm}$ (Frangi et al. 2004).

La cordillera fueguina se extiende en estrecha cercanía a lo largo de la costa, aunque en este sector de Moat la altura del cordón cordillerano decrece en relación con los tramos más occidentales y el paisaje se torna paulatinamente más abierto, con elevaciones que varían entre 100 y 900 m s.n.m. Existen varios cursos fluviales que descargan en el mar, pero el río Moat (figura 1) es el afluente más extenso, que recorre en sentido noroeste-sureste cerca de $50 \mathrm{~km}$ del valle. El entorno es boscoso, cubierto principalmente por el género Nothofagus sp., intercalado por turberas y pastizales.

En el ámbito terrestre existen pocas especies de mamíferos autóctonos: zorros colorados (Lycalopex culpaeus), guanacos (Lama guanicoe) y algunos roedores. En la actualidad, estos animales coexisten con otras especies introducidas, como el zorro gris (Lycalopex griseus) y domésticas, como caballos (Equus caballus), vacas (Bos primigenius Taurus), perros (Canis lupus familiaris) y castores (Castor canadensis). En el sector litoral habita una diversidad importante de animales marinos, entre los que se incluyen pinnípedos (principalmente dos especies: Otaria flavescens y Arctocephalus australis), cetáceos, aves, peces y moluscos (Lloris y Rucabado 1991; Schiavini y Yorio 1995; Forcelli 2000; Bastida y Rodríguez 2003).

El ambiente intermareal de bahía Moat se encuentra afectado por procesos geomorfológicos ocurridos durante el Último Máximo Glaciar (Borromei et al. 2014). El extenso campo de drumlins $^{1}$ elongados en dirección S-SE es interceptado por la actual línea de costa y en algunos casos forman acantilados de hasta $50 \mathrm{~m}$ de altura. También es probable que se encuentren drumlins sumergidos o erosionados por la acción marina. Dependiendo de la ubicación de estas geoformas con respecto la línea de costa y su evolución a lo largo del Holoceno, en el sector de Moat es posible diferenciar entre: a) paleoacantilados, aquellos que ya no son alcanzados por el mar (por sedimentación en su base, ascenso tectónico o descenso eustático) y continúan su evolución como laderas continentales; b) acantilados estabilizados, embestidos únicamente durante tormentas y otros eventos excepcionales, comúnmente poseen pendientes más suaves por la acumulación de materiales en su base y/o por la colonización por vegetación; c) acantilados activos, corresponden a aquellos que son atacados por las olas al menos durante la marea alta (Andrade et al. 2004).

Niveles elevados de paleoplayas fueron reconocidos sobre la costa del canal Beagle como consecuencia del acenso isostático-tectónico: las más antiguas presentan una edad cercana a los 
6.700 años cal AP (Zangrando et al. 2016), con alturas que varían desde un máximo de 8-10 m en el oeste, disminuyendo hacia el este a alturas cercanas a los $5 \mathrm{~m}$ en bahía Cambaceres (Rabassa $e t$ al. 2000; Zangrando et al. 2016). En Moat, el modelo paleogeográfico muestra que hacia los 7.000 años cal AP el sector adquirió las características geográficas actuales, pero hasta el momento no han sido descritas playas elevadas del Holoceno (Borromei et al. 2014). Es posible que el manto de hielo haya sido menos denso que hacia el oeste del canal Beagle, de modo que la liberación de su peso pudo haber generado un efecto rebote más leve y levantamientos del terreno menores (Borromei et al. 2014).

\section{ESPACIO SUPRAMAREAL E INTERMAREAL: EXPECTATIVAS TAFONÓMICAS}

El sector prospectado abarca aproximadamente $5 \mathrm{~km}$ longitudinales de costa, desde S5456'26,79”, O6654'43,96”' a S5457'14,68”, O6649'5,52”. Las playas son en su mayoría de gravas y se encuentran interrumpidas por drumlins. Las transectas cubrieron el nivel intermareal y supramareal de acuerdo con la zonación propuesta por Grosso et al. (2019). El primero es el espacio comprendido entre niveles de pleamar y bajamar de sicigias. Al estar influido por el vaivén de las olas, no existe vegetación, pero se presentan bancos de macroalgas (Macrocystis pyrifera) que suelen ser abundantes luego de períodos de tormenta. En el intermareal se prospectó el horizonte superior (sensu Grosso et al. 2019), dado que aquí hay una mayor tendencia hacia la acumulación de materiales, los cuales a su vez pueden alcanzar los espacios más aledaños a los sitios arqueológicos.

Por encima de los niveles de pleamar de sicigias se ubica el supramareal (Grosso et al. 2019), que es el espacio de transición entre el ambiente marino y el terrestre. Es un sector totalmente expuesto, pero durante las pleamares equinocciales o en situaciones extraordinarias donde se combinan pleamares de sicigias con temporales, puede quedar inundado su horizonte inferior por breves períodos. Entre el horizonte superior del intermareal y el supramareal es común la formación de bermas, que constituyen los sectores más elevados adyacentes al frente de las playas (Arche 2010). El agua solo cubre la berma en marea alta o cuando la energía del viento apila agua sobre la orilla. En estos depósitos acontecen los eventos más importantes de acumulación de sedimentos y materiales. La superficie del supramareal está comprendida por gravas y algunos espacios con desarrollo variable de pastos y matorrales, motivo por el cual suele haber bioturbación por raíces de plantas y otros organismos terrestres. El supramareal se extiende hacia el interior hasta el límite de penetración de las influencias marinas (Bird 2011). Las características que adquiere el terreno detrás del supramareal son variables y responden a cambios en la fisiología del paisaje como acantilados, presencia de terreno ascendente detrás de las tierras bajas costeras, lagunas, campos de pastizales o turberas. En la zona de estudio, algunos de estos espacios presentan paleoplayas de guijarros cuyas superficies están cubiertas por vegetación. En algunas incluso puede distinguirse la formación de antiguos cordones litorales situados por encima de la zona mareal actual, los cuales fueron resultado de eventos de transgresión-regresión marina acontecidos durante el Holoceno producto de la Última Máxima Glaciación (Rabassa et al. 2000). Los sitios arqueológicos suelen estar ligeramente por encima del nivel de las mareas altas, por lo que se ubican tanto en la zona supramareal como en el sector inmediatamente posterior aquí descripto. Existen, asimismo, sitios localizados en contextos boscosos y alejados de las influencias de mar, a aproximadamente 300-200 m desde la línea de la costa actual (Zangrando 2010). En su mayoría, los depósitos son concheros con extensiones y aspectos superficiales variables, ubicados en distintas geoformas (e.g., drumlins, paleoplayas, acantilados). Los análisis radiocarbónicos hasta el momento disponibles indican cronologías correspondientes al Holoceno tardío (ca. 1000-200 años AP; Alunni y Zangrando 2012). 
En términos generales, las costas de bahía Moat son confinadas (sensu Martínez 2001) dado que la presencia de los acantilados arriba descriptos, en conjunto con la densa vegetación lindante, restringen o impiden la migración de materiales y sedimentos hacia el interior. Existen, no obstante, algunos espacios más amplios donde los procesos de transgresión/regresión arriba mencionados dieron lugar a la formación de paleoplayas y sucesivos cordones litorales. Por lo tanto, la línea que dibuja la costa del área de estudio es irregular, a lo largo de la cual se alternan playas largas semi-rectilíneas de suave pendiente con afloramientos rocosos, tramos más abruptos con bahías y cantidad de ensenadas menores, además de caletas reparadas.

Los procesos de transporte y acumulación de materiales están estrechamente relacionados con las características de las mareas, el oleaje y la orientación de la línea litoral (Martínez 2001). La zona presenta un régimen micromareal y semidiurno con desigualdades diurnas, con una amplitud media de 1,1 m (Servicio de Hidrografía Naval 2002). Las costas están principalmente expuestas a los vientos del sudoeste que generan una gran repercusión al influir en la dirección del oleaje y en el transporte sedimentario asociado. No obstante, como las condiciones locales varían a lo largo del año, las playas pueden experimentar derivas litorales opuestas, incluso en el lapso de unos pocos días (Arche 2010). La frecuencia anual de los vientos es de 23,6\% y la velocidad media de $31 \mathrm{~km} / \mathrm{h}$ (Isla et al. 1999), formándose olas irregulares de período corto (1 a 3") y rompientes de volteo con alturas máximas de $0,5 \mathrm{~m}$ (Bujalesky et al. 2004). Si bien la energía del oleaje no es demasiado alta, como la pendiente de la zona sublitoral suele ser alta, el accionar de las olas se aplica a toda la playa y genera grandes depósitos de gravas, restos de animales muertos y residuos antrópicos. Además, los fuertes vientos promueven estos eventos de acumulación. El 50\% de los días del año, las ráfagas superan $50 \mathrm{~km} / \mathrm{h}$; 10 días al año superan los $100 \mathrm{~km} / \mathrm{h}$ y pueden llegar, excepcionalmente, a $200 \mathrm{~km} / \mathrm{h}$ (Iturraspe y Schroeder 2015).

Por lo antedicho, la variabilidad que existe sobre los distintos tipos de playas genera diferentes posibilidades para la acumulación de materiales. Observaciones tafonómicas desarrolladas en Patagonia meridional y en la costa Atlántica de Tierra del Fuego advirtieron sobre diferencias en el grado de acumulación de restos óseos que dependen de la energía de transporte del flujo hídrico (Borella y Favier Dubois 1994-95; Borella 2004). Asimismo, se observó que existe una alta diversidad en las características de las acumulaciones naturales a lo largo de la costa (Muñoz et al. 2016). Por ejemplo, las playas frente al mar abierto reciben un aporte diacrónico continuo de huesos y pueden presentar incorporación y re-exposición de elementos al sustrato, mientras que en los espacios ubicados en el interior de las bahías el corpus principal estaría dado por carcasas de mamíferos marinos muertos simultáneamente (Borella y Muñoz 2006). Esto, a su turno, tiene un correlato visible en cuanto a la representación anatómica y al estado de preservación de las muestras, que difiere según el tipo de costa. Existen diferentes tasas de meteorización (sensu Behrensmeyer 1978) para los diversos taxones (e.g. entre cetáceos y mamíferos terrestres, entre pinnípedos y guanacos, entre aves y mamíferos). Asimismo, se observó que en los sectores con alta cobertura vegetal el grado de entierro de elementos óseos es mayor, hecho que incrementa las posibilidades de mezcla entre materiales arqueológicos y fauna actual si se lo compara con superficies de escasa vegetación. Sin embargo, hay determinadas propiedades del registro que facilitarían la diferenciación entre las acumulaciones naturales de aquellas formadas por la acción antrópica (e.g., integridad anatómica, perfil etario de los individuos representados, huellas culturales, meteorización, etc.) (Borella y Muñoz 2006; Muñoz et al. 2016).

Por lo tanto, partimos de la hipótesis de que los procesos tafonómicos adquieren magnitudes y patrones variables conforme fluctúan las características fisiográficas y geomorfológicas costeras. Nuestra expectativa es que la abundancia y diversidad de materiales óseos acumulados varíe según el sector y el contorno costero, pudiendo afectar de manera diferente los procesos de formación de sitios arqueológicos. El transporte litoral tiende a retener lo transportado en sus zonas entrantes, pero se reduce en los tramos más centrales, particularmente en aquellas playas semi-rectilíneas y 
que presentan rebordes convexos más expuestos al vaivén de las olas (Martínez 2001). Por este motivo, los datos serán analizados y comparados en función de la siguiente subdivisión del área: a) playas semi-rectilíneas lindantes con paleoacantilado vegetado, b) playas en herradura lindantes con paleoacantilado vegetado, c) playas semi-rectilíneas lindantes con pastizal o bosque, d) playas en herradura lindante con pastizal o bosque, e) playas convexas lindantes con pastizal, f) playas convexas lindantes con acantilados estabilizados (figura 2). Dentro de esta subdivisión, se han considerado las diferencias que puedan existir entre los tramos centrales y extremos occidentales y orientales de las playas.

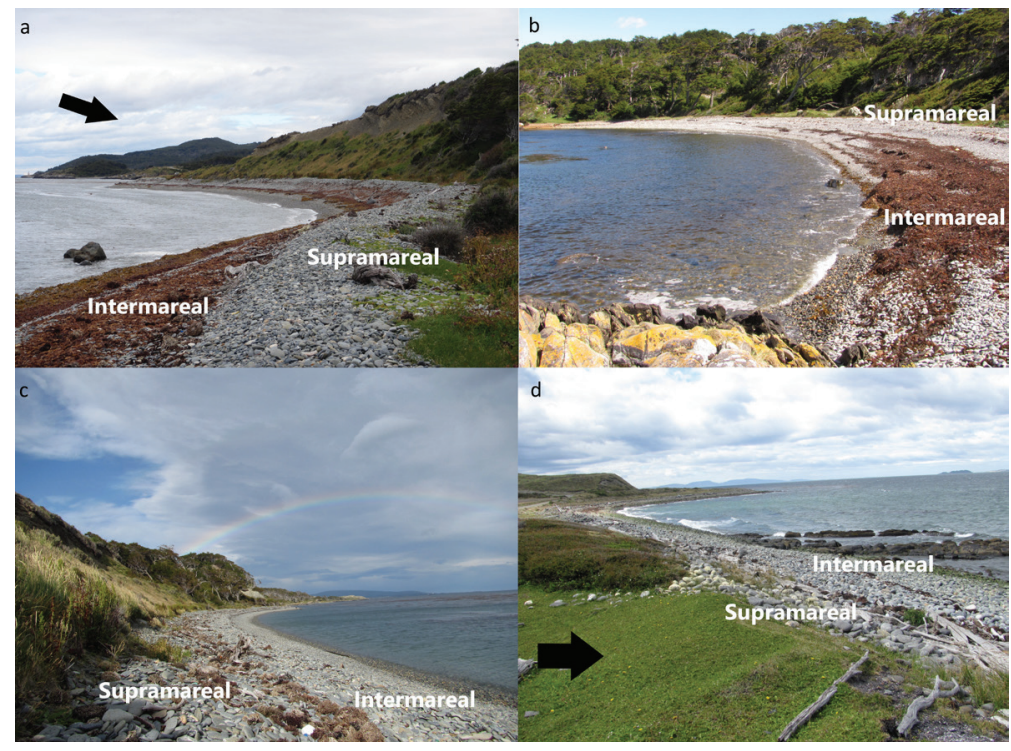

Figura 2. Algunos ejemplos de playas prospectadas en bahía Moat: a) la flecha indica el sector de playa que se torna convexo y continúa del otro lado del acantilado; b) playa en herradura lindante con bosque; c) playa semi-rectilínea lindante con acantilado vegetado; d) playa semi-rectilínea lindante con pastizal, al fondo la playa se torna convexa y continúa adyacente a un acantilado. La flecha señala la ubicación de un conchero

\section{MATERIALES Y MÉTODOS}

Las tareas de investigación se efectuaron en dos momentos: septiembre de 2019 y marzo de 2020. Se prospectaron los mismos espacios en estos diferentes meses y se cubrieron iguales superficies. Se siguieron los criterios metodológicos propuestos por Massigoge et al. (2015). El relevamiento se desarrolló a través de transectas con una longitud máxima de 500 m y un ancho de $20 \mathrm{~m}$ según el grado de visibilidad o la extensión de la geoforma. Cada transecta fue recorrida por dos personas. Éstas cubrieron las diferentes unidades del paisaje arriba mencionadas, se distinguió entre los distintos tipos de costa y se documentó el ambiente sedimentario en cuestión: pendiente (nula, baja, media, alta), tipo de sedimento, potencial de enterramiento (nulo, bajo, alto), presencia de agua (ausencia, río, encharcamiento, empantanado, escorrentía), vegetación (tipo, distribución y grado de visibilidad). Asimismo, se registró la presencia/ausencia de bioturbación (e.g., vegetales, roedores, pisoteo, carnívoros, caballos, etc.), fauna actual, actividad antrópica moderna y evidencia arqueológica.

Los hallazgos fueron clasificados como "hueso aislado" (elementos dispersos), "concentración" (<75\% del esqueleto articulado y unido por tejido blando) y "carcasa" ( $>75 \%$ del 
esqueleto articulado y unido por tejido blando). Los restos faunísticos fueron descriptos in situ, fotografiados y georreferenciados para confeccionar mapas de dispersión con un Sistema de Información Geográfica (ArcMap 10.1). Luego, para lograr un nivel más alto en la determinación taxonómica y anatómica, y evaluar con mayor grado de detalle las modificaciones de los huesos, se recolectaron todos aquellos elementos que se encontraron desarticulados y la mayoría de los articulados. Los que no pudieron ser llevados al laboratorio fueron analizados con detalle in situ. Se registraron las siguientes características para cada hallazgo: taxón, elemento, grado de completitud (si se hallaron enteros o fragmentados), grado de fusión y lateralidad. Por otra parte, se evaluó el estado del hueso en el momento de hallarlo: presencia/ausencia de tejido blando, estadio de meteorización (sensu Behrensmeyer 1978), marcas de carnívoros (Binford 1981), grado de abrasión (Fernández-Jalvo y Andrews 2003). Sobre esta última variable, se siguió la propuesta de Gutiérrez y Kaufmann (2007), quienes definieron tres niveles de abrasión y pulido: estadio 1 -presencia de brillo y textura suave-, estadio 2 -presencia de bordes romos (puede existir brillo y textura suave)- y estadio 3 -existe remoción del tejido externo y puede haber exposición de tejido trabecular en aquellos huesos que lo contengan (por ejemplo, vértebras, epífisis)-. Dado que estas categorías fueron establecidas para ambientes fluviales de flujo lento de la provincia de Buenos Aires, en este trabajo son utilizadas con fines descriptivos sobre los rasgos observados en las superficies óseas, pero no representan criterios válidos para inferir trayectorias de transporte.

Los restos faunísticos se cuantificaron, para lo cual se utilizaron las medidas de abundancia taxonómica (NISP y MNI) (Klein y Cruz-Uribe 1984). Estos estudios fueron las vías de entrada para evaluar los patrones de dispersión de cada especie faunística y si existen sesgos diferenciales en el transporte/acumulación de determinados elementos que puedan relacionarse con sus formas y tamaños específicos. Para evaluar el rol de la selección hídrica en la representación anatómica de guanacos, se compararon las frecuencias relativas de los elementos que integran el grupo 1 (es decir, huesos con alto potencial de transporte) y el grupo 3 (es decir, huesos con baja probabilidad de transporte) (ver Kaufmann et al. 2011: tabla 7).

\section{RESULTADOS}

Se prospectó un total de $51.730 \mathrm{~m}^{2}$. Se hallaron 299 especímenes aislados, 15 concentraciones y cinco carcasas (tabla 1). Existen diferencias entre las proporciones de restos recolectados en el supramareal y el horizonte superior del intermareal: de los aislados, el 30\% corresponde al primer sector y el $70 \%$ al segundo, las concentraciones se distribuyen entre $47 \%$ y $53 \%$, respectivamente; y todas las carcasas se recuperaron en el intermareal. Las playas semi-rectilíneas, ya sean aquellas que lindan con paleoacantilados, acantilados estabilizados, pastizales o bosques, presentan la mayor densidad de restos óseos, siendo menor en los espacios semi-rectilíneos con contornos convexos lindantes con pastizal y en las playas en herradura. Como puede observarse en la tabla 1, los huesos tienden a acumularse en su mayoría en los tramos orientales de las costas, con menores frecuencias hacia el centro y el oeste.

En cuanto a las representaciones taxonómicas, las aves predominan en los conjuntos óseos (principalmente Phalacrocoracidae, Spheniscidae y Anatidae), seguidos por guanacos, pinnípedos, vacas, caballos y ovejas. También fueron identificados cánidos y castores, pero en números muy bajos (1 y 2, respectivamente); no fueron contemplados en el análisis tafonómico porque generan distorsión al compararlos con tamaños de muestra más grandes. Las localizaciones de las concentraciones coinciden con los espacios donde existe mayor frecuencia de restos; doce de éstas corresponden a aves (en su mayoría articuladas y con tejido blando), dos de vértebras y costillas de pinnípedos (una de estas concentraciones se halló en posición articulada, pero sin tejido blando) y la otra corresponde a vértebras y costillas de ganado sin articular. En cuanto a 
Tabla 1. Distribución y densidad restos óseos en las distintas unidades del paisaje consideradas

\begin{tabular}{|c|c|c|c|c|c|c|c|}
\hline Tipo de playa & $\begin{array}{c}\text { Oeste: } \\
\text { NISP } \\
\text { aislados }\end{array}$ & $\begin{array}{c}\text { Centro: } \\
\text { NISP } \\
\text { aislados }\end{array}$ & $\begin{array}{c}\text { Este: } \\
\text { NISP } \\
\text { aislados }\end{array}$ & Concentraciones & Carcasas & $\begin{array}{c}\mathrm{m}^{2} \text { cubierto } \\
\text { por } \\
\text { transecta }\end{array}$ & \begin{tabular}{|c} 
Densidad \\
aislados \\
$\left(\mathbf{m}^{2}\right)$ \\
\end{tabular} \\
\hline $\begin{array}{l}\text { Playa semi- } \\
\text { rectilínea } \\
\text { lindante con } \\
\text { paleoacantilado } \\
\text { vegetado }\end{array}$ & 12 & 37 & 59 & 0 & 0 & 1340 & 0,08 \\
\hline $\begin{array}{l}\text { Playa semi- } \\
\text { rectilínea } \\
\text { lindante con } \\
\text { pastizal o bosque }\end{array}$ & 25 & 21 & 33 & 6 & 1 & 1000 & 0,08 \\
\hline $\begin{array}{l}\text { Playa en } \\
\text { herradura } \\
\text { lindante con } \\
\text { pastizal o bosque }\end{array}$ & 15 & 18 & 15 & 3 & 0 & 1322 & 0,04 \\
\hline $\begin{array}{l}\text { Playa en } \\
\text { herradura } \\
\text { lindante con } \\
\text { paleoacantilado } \\
\text { vegetado }\end{array}$ & 0 & 0 & 28 & 5 & 2 & 811 & 0,03 \\
\hline $\begin{array}{l}\text { Playa semi- } \\
\text { rectilínea } \\
\text { convexa lindante } \\
\text { con pastizal } \\
\end{array}$ & 0 & 0 & 3 & 0 & 0 & 350 & 0,008 \\
\hline $\begin{array}{l}\text { Playa semi- } \\
\text { rectilínea } \\
\text { convexa lindante } \\
\text { con acantilado } \\
\text { estabilizado } \\
\end{array}$ & 17 & 0 & 16 & 5 & 2 & 350 & 0,09 \\
\hline
\end{tabular}

las carcasas, tres son de aves y una de castor. Los restos en general fueron hallados sin presencia de tejido blando y desarticulados $(94,8 \%, \mathrm{n}=283)$. Las aves fueron las que presentaron mayor grado de articulación entre sus elementos $(n=12)$ y registraron presencia de tejido blando $(n=13)$. En los restos óseos desarticulados correspondientes a mamíferos se pudo determinar el grado de fusión en 77 especímenes, entre los cuales el 97,4\% se hallaron fusionados, a excepción de dos vértebras de pinnípedos (una semifusionada y otra sin fusionar). En los guanacos solo se reconocieron individuos adultos y subadultos.

Los restos óseos recolectados en el año 2019 estaban distribuidos en forma más dispersa en el paisaje que los obtenidos en el año 2020. Un aspecto que pudo haber influido es el tiempo de acumulación dado que, en prospecciones anteriores realizadas durante el año 2016, se habían efectuado recolecciones de huesos (Alunni et al. 2017). Es decir, transcurrieron tres años hasta que se reanudaron las observaciones actualistas en el sector. Esto puede verse reflejado en la proporción de especímenes obtenidos en los distintos años dado que, del total presentado en la tabla 1, el 60\% proviene de las transectas del año 2019. Por otra parte, si bien los huesos aparecen dispersos de manera relativamente continua a lo largo del litoral, existen zonas con depósitos marcadamente mayores y otras en donde no se registraron huesos en ninguno de los muestreos efectuados (tabla 1, figura 3). 
Relaciones de la Sociedad Argentina de Antropología 46 (2), julio-diciembre 2021: 657-680

Tabla 2. Abundancia taxonómica (NISP y NISP\%) de las especies faunísticas halladas en las transectas

\begin{tabular}{|l|c|c|c|c|c|c|c|}
\hline \multirow{2}{*}{ Taxón } & \multicolumn{2}{|c|}{ Aislado } & \multicolumn{2}{c|}{ Concentración } & \multicolumn{2}{c|}{ Carcasa } & MNI \\
\cline { 2 - 8 } & NISP & NISP\% & Ocurrencias & Ocurrencias \% & Ocurrencias & Ocurrencias\% & \\
\hline Ave & 188 & 62,9 & 12 & 80 & 4 & 75 & 27 \\
\hline Castor & 1 & 0,3 & 0 & 0 & 1 & 25 & 2 \\
\hline Pinnípedo & 31 & 10,4 & 2 & 13,3 & 0 & 0 & 3 \\
\hline Cánido & 2 & 0,7 & 0 & 0 & 0 & 0 & 1 \\
\hline Guanaco & 36 & 12 & 0 & 0 & 0 & 0 & 5 \\
\hline Vaca/caballo & 25 & 8,4 & 1 & 6,7 & 0 & 0 & 2 \\
\hline Oveja & 16 & 5,4 & 0 & 0 & 0 & 0 & 1 \\
\hline Total & 299 & - & 15 & - & 5 & - & 38 \\
\hline
\end{tabular}

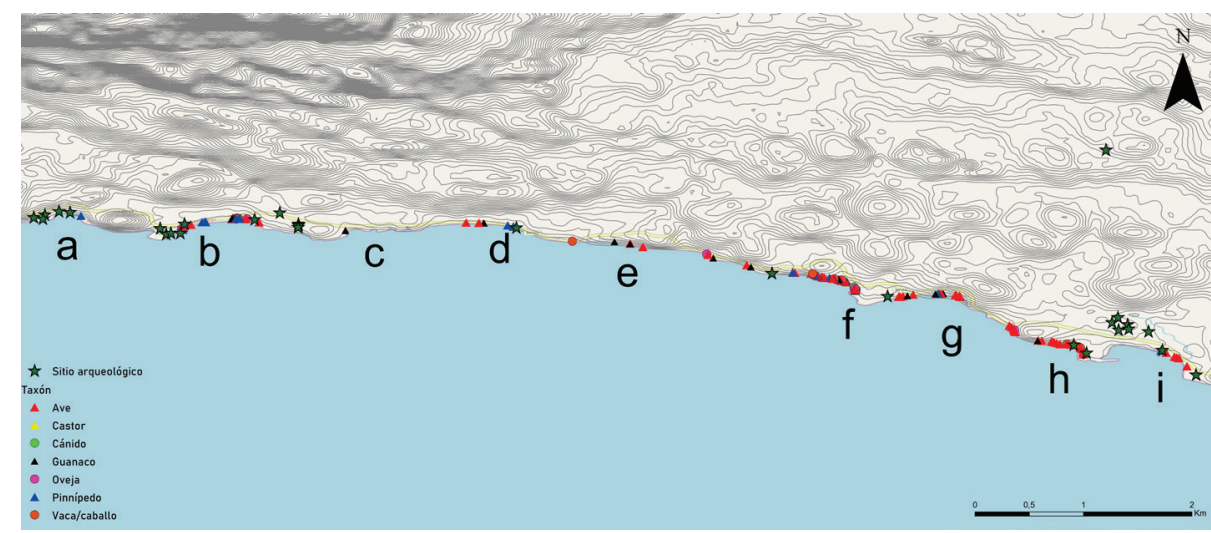

Figura 3. Distribución taxonómica, de especímenes hallados por espacio prospectado y de sitios arqueológicos. Las referencias alfabéticas corresponden a los sectores con hallazgos ampliados en la figura 4

En términos taxonómicos, las aves, guanacos, mamíferos, ovejas, cánidos y castores no presentan una tendencia específica de dispersión, sino que están distribuidos de manera regular sin ningún patrón definido por tipo de costa (figura 4). La mayoría de los pinnípedos, en cambio, aparecen concentrados a lo largo de dos playas (figuras $4 \mathrm{~b}$ y f). En una de ellas, sus restos se hallaron en un diámetro aproximado de $250 \mathrm{~m}$, mientras en la otra a lo largo de $350 \mathrm{~m}$ de costa. La relación entre los huesos de pinnípedos recolectados en ambas playas es analizada más abajo.

Solo el 3\% de la muestra se halló enterrada o semienterrada, mientras los restantes huesos permanecían expuestos, la mayoría entre guijarros de playa. El 31,4\% (n=94) del total de especímenes aislados se encuentran fragmentados. Si se consideran las proporciones de especímenes fragmentados sobre el total de cada grupo taxonómico (tabla 2), los guanacos registraron mayores niveles de fragmentación $(55,6 \%, \mathrm{n}=20)$. A estos le siguen las ovejas $(56 \%, \mathrm{n}=9)$, las vacas y caballos $(40 \%, \mathrm{n}=10)$, las aves $(26,6 \%, \mathrm{n}=50)$ y finalmente los pinnípedos $(16 \%, \mathrm{n}=5)$. Entre las 15 concentraciones, solo en una de aves se registró signos de abrasión (estadio 1). En cambio, de los hallazgos aislados, solo un 33,4\% (n=99) de los huesos aislados no presenta indicios de 
DANIELA V. ALUNNI Y OTRos - DistribuCión NATURAL DE RESTOS ÓSEOS EN LA FRANJA INTERMAREAL DEL SUR ...

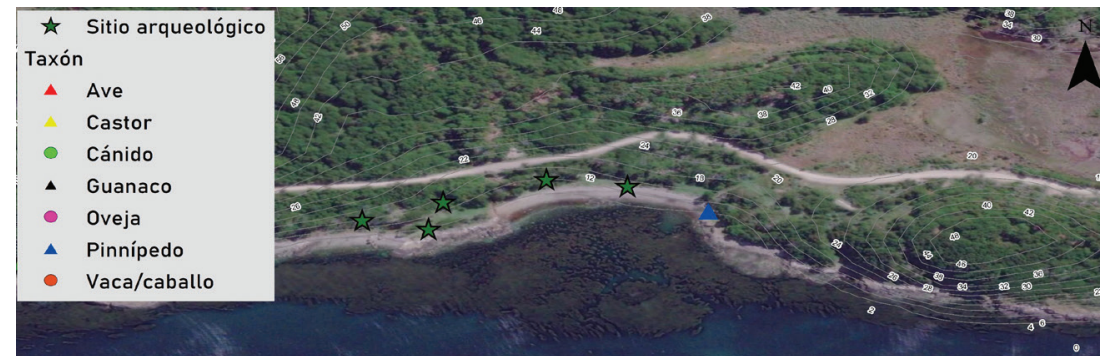

a

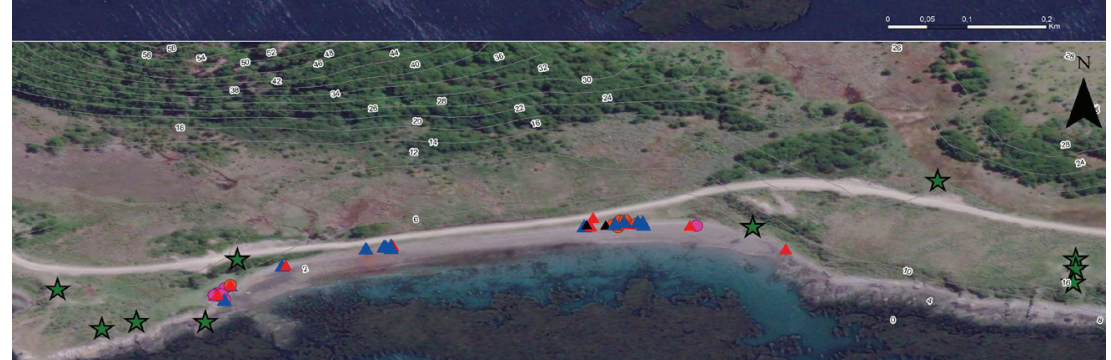

b
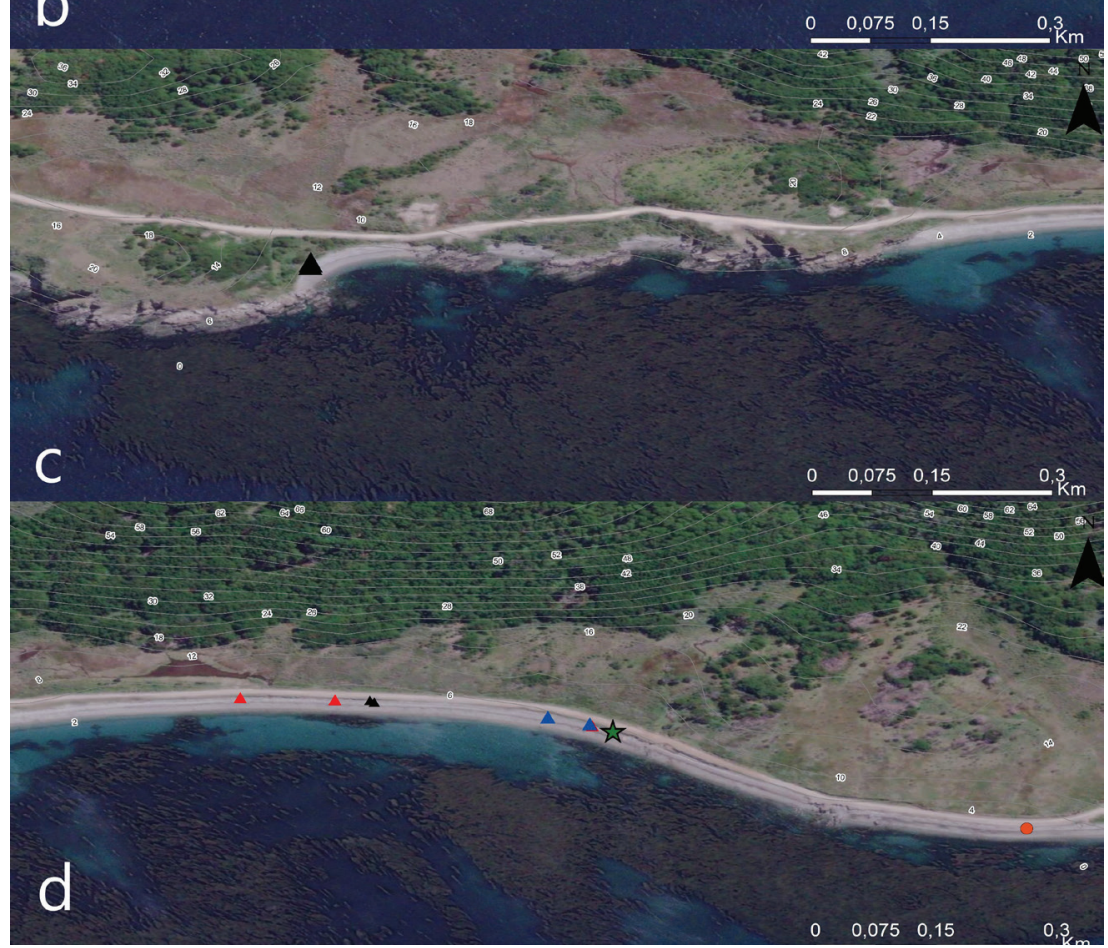

Figura 4. Distribución de sitios arqueológicos y restos óseos actuales por taxones. Las ampliaciones muestran las localizaciones en sectores donde hay mayores acumulaciones 
Relaciones de la Sociedad Argentina de Antropología 46 (2), julio-diciembre 2021: 657-680

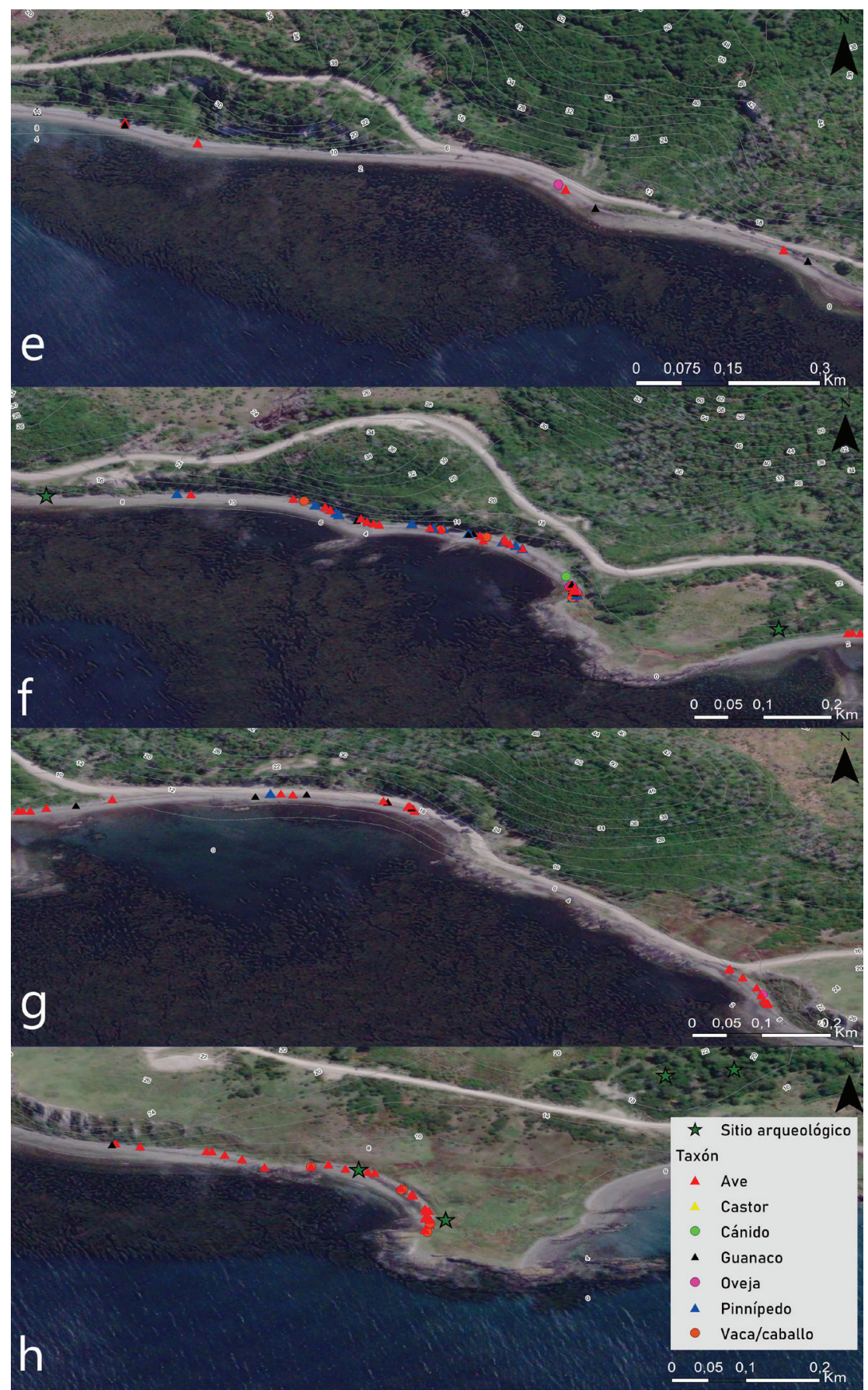

Figura 4 (continuación). Distribución de sitios arqueológicos y restos óseos actuales por taxones. Las ampliaciones muestran las localizaciones en sectores donde hay mayores acumulaciones 


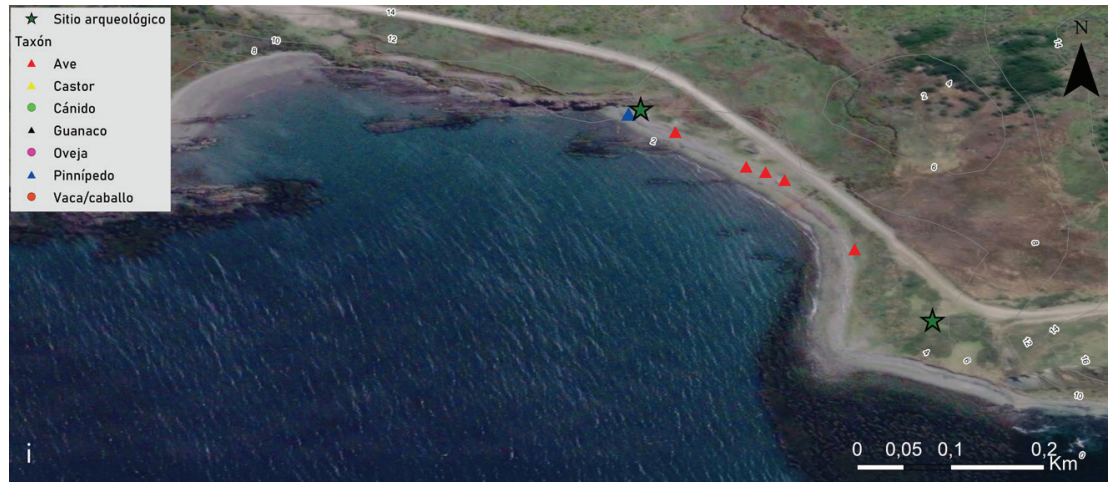

Figura 4 (continuación). Distribución de sitios arqueológicos y restos óseos actuales por taxones. Las ampliaciones muestran las localizaciones en sectores donde hay mayores acumulaciones

este efecto tafonómico, mientras que los restantes especímenes exhibieron estadios $1(38,5 \%), 2$ $(18,2 \%)$ y $3(9,8 \%)$. No resulta posible establecer un patrón de dispersión de huesos según su grado de abrasión, sino que los distintos niveles se muestran indistintamente en el espacio. La figura 5 muestra que la expresión de esta variable parece ser diferente entre las aves y los mamíferos. En todos los casos siempre predominan los elementos abradidos pero, a diferencia de las aves, en los mamíferos se observa una mayor proporción de huesos con remoción completa del tejido cortical.

Se analiza la relación entre los especímenes fragmentados y la abrasión. Entre los huesos fragmentados de vacas/caballos y guanacos, el $80 \%$ poseen bordes con rasgos de abrasión; en pinnípedos este porcentaje es de $60 \%$, en ovejas $56 \%$ y en aves $44 \%$.

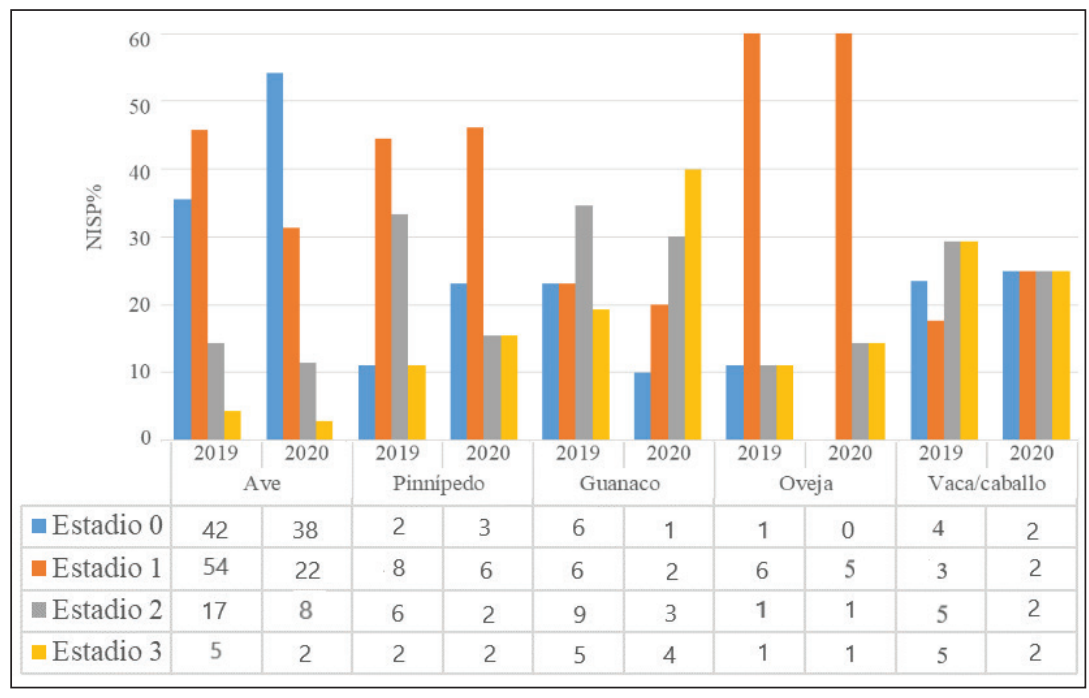

Figura 5. Distribución de las frecuencias de huesos con abrasión discriminados por taxón (hallazgos aislados)

En términos generales, los restos óseos exhiben nula meteorización y estadios bajos (figura 6). La expresión de esta variable se manifiesta de manera disímil entre los taxones. Como puede observarse en la figura 6, en los mamíferos los estadios más avanzados son más frecuentes que en las aves. Esta tendencia es incluso más evidente a medida que aumenta el tamaño del animal. 
Al igual que lo observado por Muñoz et al. (2016) al sur del río Santa Cruz, el número de huesos de pinnípedos en estadios más meteorizados es mayor que el registrado para guanacos (figura 6). Esto se debe a que la desarticulación de las carcasas de pinnípedos demora más tiempo que las de camélidos como consecuencia de la resistencia de la gruesa capa de cuero a descomponerse (Muñoz et al. 2016). Con el fin de evaluar si los efectos de la meteorización pudieron enmascararse por la abrasión eólica y marina se correlacionaron ambas variables utilizando el coeficiente de rho Spearman. En aves, el resultado fue débil y estadísticamente no significativo $\left(r_{\mathrm{s}}=0,2\right.$ p-valor $>0,05)$, mientras en mamíferos la fuerza de la correlación fue débil pero estadísticamente significativa $\left(r_{\mathrm{s}}=0,2 \mathrm{p}\right.$-valor $\left.<0,001\right)$.

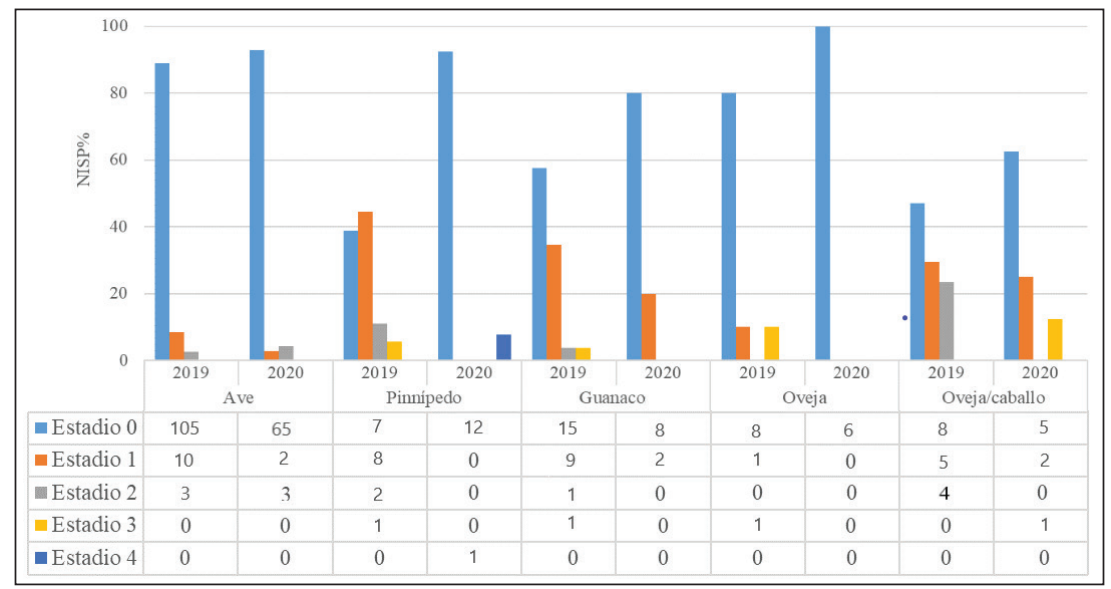

Figura 6. Distribución de las frecuencias de estadios de meteorización discriminados por taxón

La actividad carroñera se reconoció en tres concentraciones de ave y 19 especímenes óseos aislados. Los tipos de rastros observados fueron hoyuelos y bordes crenulados. Entre los elementos articulados con tejido blando y sin abrasión, el accionar de los carnívoros se registró en una carcasa de castor y en tres concentraciones de aves. Como estos elementos no poseen signos de transporte hídrico, se sugiere que habrían sido carroñeados in situ o en un radio cercano dentro de la misma playa donde perecieron los animales. Los restantes 19 casos se distribuyen en especímenes aislados correspondientes a cuatro huesos de ave (tres esternones y un húmero), cuatro de guanaco (dos escápulas, un fémur y una mandíbula), ocho de oveja (costillas mediales-distales), uno de pinnípedo (costilla) y uno de vaca/caballo (cráneo). Estos especímenes se encontraron con evidencias de abrasión, lo que sugiere que la actividad carroñera habría ocurrido con anterioridad al transporte por mar. Finalmente, el pisoteo fue otro efecto tafonómico que se reconoció en varios especímenes, sobre todo en los esternones $(n=14)$ y sinsacro/pelvis $(n=4)$ de aves. También se observó en una escápula de guanaco y en una hemimandíbula de caballo.

Con respecto a la abundancia anatómica de los taxones más representados, existe entre los mamíferos una tendencia hacia la escasa o nula presencia de elementos pequeños, por ejemplo, dientes, falanges y articulares, y una mayor frecuencia de huesos con mayor tamaño (tabla 3). Con los restos de aves sucede algo similar a lo observado con los mamíferos: se advierte escasa o nula frecuencia de elementos pequeños y, por el contrario, mayor recurrencia de sus huesos más grandes. Se destaca una diferencia observada entre las representaciones anatómicas de guanacos y pinnípedos que, por ser taxones habituales en los conjuntos zooarqueológicos de la zona, puede tener implicancias sobre la conformación de estos depósitos. La tabla 3 muestra que los elementos más frecuentes entre los camélidos provienen de la región apendicular, los cuales suelen tener mayor 
densidad mineral ósea y ser propensos a preservarse por períodos de tiempo más prolongados que los huesos con valores densitométricos bajos (Elkin 1995). El grado de abrasión de estos elementos y su general disposición como especímenes aislados, sin tejidos blandos y desarticulados, propone al agua como principal responsable de estas acumulaciones. Asimismo, el 52,7\% de las unidades anatómicas de guanacos aquí identificadas corresponden al grupo 3 definido por Kaufmann et al. (2011), de modo que estos pudieron haber sido acarreados en contextos de alta energía. En los pinnípedos, en cambio, predominan especímenes axiales y menos densos (Borella et al. 2007). En el próximo acápite se discutirá sobre las posibles trayectorias de transporte de los mamíferos.

Tabla 3. Representación de unidades anatómicas de los principales taxones

\begin{tabular}{|c|c|c|c|c|c|}
\hline & Ave & Pinnípedo & Guanaco & Vaca/caballo & Oveja \\
\hline Cráneo $^{2}$ & 3 & 2 & 2 & 1 & - \\
\hline Mandíbula $^{2}$ & & 2 & 1 & 1 & - \\
\hline Vértebra $^{1 *}$ & 7 & 14 & 7 & 8 & 2 \\
\hline Sacro $^{1}$ & 18 & & & & \\
\hline Costilla $^{2}$ & 2 & 4 & 2 & 11 & 9 \\
\hline Coracoides & 11 & - & - & - & - \\
\hline Fúrcula & 9 & - & - & - & - \\
\hline Fíbula & 4 & - & - & - & - \\
\hline Clavícula & 5 & - & - & - & - \\
\hline Pelvis & 5 & 1 & - & 1 & - \\
\hline Esternón ${ }^{1}$ & 24 & & - & - & - \\
\hline Escápula & 4 & 1 & 9 & - & - \\
\hline Húmero $^{2}$ & 39 & & 1 & - & - \\
\hline Radio & 7 & 3 & - & - & - \\
\hline Cúbito & 15 & & - & - & - \\
\hline Carpometacarpo & 5 & - & - & - & - \\
\hline Radio-cúbito ${ }^{2}$ & - & - & 4 & - & - \\
\hline Calcáneo $^{2}$ & - & 1 & & - & - \\
\hline Fémur & 7 & - & 3 & - & 2 \\
\hline Tibia $^{2}$ & & - & 2 & 2 & - \\
\hline Tibiotarso & 19 & - & - & - & - \\
\hline Hueso largo & 4 & - & 1 & - & 2 \\
\hline Articular & - & - & 1 & - & \\
\hline Metapodio $^{2}$ & - & 3 & 3 & - & 1 \\
\hline Falange $^{2}$ & - & - & - & 1 & - \\
\hline
\end{tabular}

${ }^{1}$ Unidades anatómicas pertenecientes al "grupo 1" definido por Kaufmann et al. (2011);

2 Unidades anatómicas pertenecientes al "grupo 3" definido por Kaufmann et al. (2011);

* Las vértebras torácicas, lumbares y caudales forman parte del grupo 1, mientras el axis y las vértebras cervicales son del grupo 3 . 
Se examinaron separadamente las dos acumulaciones de pinnípedos halladas en las playas en herradura previamente mencionadas (figuras 4 y 5), con el fin de evaluar si esta disposición actual fue el resultado de varamientos puntuales acontecidos en estos lugares. En ambos casos, se reconocieron dos individuos: uno perteneciente a Otaria flavescens y otro a Arctocephalus australis. De una de las bahías proviene una concentración de vértebras y costillas articuladas, con claras evidencias de acción de carnívoros sobre los sectores mediales de estas últimas. Los demás restos aparecen dispersos, con estadios similares de meteorización ( 0 y 1$)$ pero con rasgos variables de abrasión (0 a 2). Con excepción de una costilla, los restantes especímenes no exhibieron marcas de carnívoros. En la otra bahía solo se encontraron elementos aislados y que presentan distintos grados de meteorización (que van desde el estadio 0 al 4) y abrasión (del 1 al 3). Si consideramos estas evidencias, se plantea entonces que las concentraciones de pinnípedos habrían sido producto de distintos episodios de acumulación.

Por último, veinte montículos (concheros) identificados a partir de las primeras prospecciones en el área (Zangrando et al. 2010) se ubican a lo largo de los $5 \mathrm{~km}$ de la zona prospectada. Seis de ellos fueron localizados en la línea supramareal a distancias longitudinales que oscilan entre los 5 y 100 m de los restos óseos depositados naturalmente. Algunos de estos sitios se encuentran fuertemente alterados por la erosión marina, dado que el avance y retroceso de las olas genera un paulatino desmoronamiento de los montículos. En un trabajo anterior, incluso se ha señalado la presencia de mezcla entre restos arqueológicos y actuales debido al sedimento que sustrae y remueve el mar (Alunni et al. 2017). Siete sitios se encuentran retirados de las líneas de la costa actual, sobre antiguas geoformas marinas, entre 10 y $40 \mathrm{~m}$ de distancia de huesos depositados naturalmente. Por último, siete montículos están localizados sobre acantilados sin influencia marina evidente, pero en donde pueden estar actuando otros procesos erosivos y biogenéticos no explorados en este trabajo. De esta información se desprende que cerca del $45 \%$ de los sitios arqueológicos registrados estuvieron expuestos a la incorporación natural de huesos durante el Holoceno tardío.

\section{DISCUSIÓN}

La dispersión de restos óseos muestra discontinuidad en su disposición a lo largo del intermareal de bahía Moat. Dentro de una misma localidad y en una extensión de $5 \mathrm{~km}$, se registra diversidad en la dinámica de acumulación de materiales. En las playas semi-rectilíneas se identificó variabilidad en la localización de estas acumulaciones como consecuencia de la dinámica diferencial de olas. En sus tramos centrales, donde la morfología costera no ofrece entrantes de mar lo suficientemente marcadas para retener en el tiempo grandes depósitos de huesos, la presencia de especímenes es menor que hacia el oeste y el este (tabla 1). Esta tendencia es incluso más marcada en los sectores convexos. En cambio, el número de especímenes en playas en herradura lindantes con pastizales o bosques parece mantener una frecuencia más constante en sus distintos espacios. Las entrantes actúan como sumideros naturales de sedimentos donde, tanto estos como los huesos transportados quedan retenidos. Se observa en general una tendencia hacia un mayor depósito de restos óseos en los tramos orientales de las playas. Este patrón podría explicarse porque los vientos predominantes son del sudoeste, entonces la energía del oleaje que ingresa al litoral generaría mayores contextos de acumulación y retención de restos óseos hacia el este. Esta situación es incluso más marcada al tratarse de playas en herradura adyacentes a acantilados, donde la abundancia de materiales es en general menor y solo se acumulan en los espacios más orientales, lo que sugiere que aquí la energía marina podría actuar de manera más significativa sobre sitios arqueológicos, generando mayores contextos de mezcla o destrucción de los depósitos. Estas playas en herradura con acantilados suelen ser más angostas que aquellas 
adyacentes a pastizales de modo que, durante la pleamar, el agua suele alcanzar la zona superior del intermareal y en muchos casos no hay formación de niveles supramareales. En este sentido, el avance y retroceso del mar genera un constante vaivén de huesos que encuentran menores posibilidades de quedar retenidos al pie de los acantilados.

La mayoría de los especímenes aislados fueron hallados en el horizonte superior del intermareal, mientras que el $30 \%$ de los hallazgos aislados alcanzan el espacio supramareal. Esto sugiere la posibilidad de mezcla entre los restos arrastrados por el mar y los depósitos arqueológicos localizados en esta línea de costa. Los sitios ubicados sobre antiguas geoformas marinas no están afectados por la acción directa del mar en la actualidad, pero la relación entre sus emplazamientos y el espacio intermareal tuvo que haber sido más próxima en el pasado. Incluso aún en las condiciones actuales, la relativa cercanía (de 10 a $40 \mathrm{~m}$ ) que hallamos entre estos conjuntos y los restos óseos del supramareal nos alerta sobre la necesidad de contemplar, durante el análisis de las muestras, posibles incorporaciones de materiales a la matriz de estos depósitos. Esto es factible si analizamos la presencia de concentraciones y carcasas que corresponden principalmente a huesos articulados de aves con tejido blando sin signos de abrasión. Esto podría estar indicando que pudieron haber perecido en el intermareal o bien en el mar para luego quedar depositadas allí por efecto de las olas. Si estos individuos llegan con carne y plumas difícilmente pueda esperarse abrasión de sus huesos bajo estas circunstancias. Las aves marinas pueden encontrar su lugar de muerte en el mar, pero quedar depositadas, por arrastre, en las playas donde continúan actuando los agentes carroñeros, encadenando así otro mecanismo de dispersión. Sobre este aspecto, Gutiérrez et al. (2016) sugirieron que las grandes acumulaciones de carcasas depositadas en el intermareal producto de muertes naturales in situ o del transporte hídrico, constituyen buenas oportunidades para carroñar. En la costa bonaerense, los autores observaron que los zorros tienden a sustraer estos huesos y transportarlos hacia áreas protegidas detrás de la línea de costa, con distancias que pueden alcanzar hasta los $670 \mathrm{~m}$ hacia el interior (Gutiérrez et al. 2016). Sería esperable entonces, que el efecto del transporte de las olas sumado al accionar de las especies carroñeras tenga como consecuencia el arrastre de huesos hacia el interior por fuera de la zona supramareal. La identificación de concentraciones de pinnípedos indica la posibilidad de que estos procesos también pudieron haber ocurrido en el caso de lobos marinos. Muñoz et al. (2016) observaron un patrón similar en la dispersión de pinnípedos, dado que sus huesos fueron hallados tanto en la berma como la playa alta o interior. Esto sugiere que otros factores, además de la acción marina, actúan sobre la desorganización de las carcasas y que, por lo tanto, existen posibilidades de mezcla de huesos arqueológicos y naturales en espacios más amplios que la línea de altas mareas (Muñoz et al. 2016).

Los taxones registrados durante las prospecciones guardan correspondencia con la disponibilidad de las especies faunísticas autóctonas actuales de la zona y que, además, son comunes de hallar en los depósitos arqueológicos. Los restos de peces, cuyo consumo humano está ampliamente documentado desde el Holoceno medio (Zangrando 2009; Corbat et al. 2020), son los únicos animales que no fueron hallados en las transectas; situación que quizá responda a un problema de visibilidad o preservación diferencial. Durante las prospecciones, no se registraron datos que sugieran episodios de mortandad en masa, sino que la diversidad taxonómica, anatómica y los indicadores tafonómicos revelan diversos momentos de acumulación. Si se considera que casi todos los especímenes presentan algún grado de abrasión marina y que, además, el patrón de dispersión ósea está relacionado con la topografía y características del oleaje, es posible inferir que la acción hídrica habría sido la principal responsable de la acumulación y dispersión de huesos. Sin embargo, los atributos tafonómicos muestran que las trayectorias de estos eventos pudieron ser distintas entre las aves y los mamíferos, lo que sugiere diferencias en las fuentes primarias de proveniencia de estas osamentas. 
Por un lado, en las aves fueron pocos los especímenes que alcanzaron algún estadio de meteorización, mientras los restantes huesos aparecen sin signos aparentes de este tipo de deterioro. Esta pauta ya había sido señalada en estudios previos realizados en la zona (Alunni et al. 2017), así como en otras investigaciones actualistas llevadas a cabo en Patagonia continental (e.g., Cruz 2008; Muñoz et al. 2016) y en la costa bonaerense (Massigoge et al. 2015; Gutiérrez et al. 2016). Estos trabajos han planteado que, debido al reducido tamaño y peso que presentan las aves, sus huesos sobreviven a la intemperie por períodos de tiempo más cortos que las osamentas de mamíferos porque se deterioran más rápidamente, antes de alcanzar estadios avanzados de meteorización. Este resultado es incluso más acelerado si las carcasas de aves son sometidas a una destrucción inicial por los carnívoros, quienes generan pérdida ósea casi completa (Behrensmeyer et al. 2003; Cruz 2008; Massigoge et al. 2015). Como ya mencionamos, los efectos de la abrasión fueron también más bajos en las aves, lo que puede estar directamente relacionado con el estado de los especímenes previo a su transporte hídrico, con el lugar de origen de los restos y con el tiempo en que fueron sometidos a la acción del oleaje. Trabajos experimentales desarrollados en mamíferos han demostrado que los huesos no meteorizados (frescos) tardan más tiempo en alcanzar grados de rodamiento más elevados que aquellos que poseen grietas o escamas como producto de la exposición a los efectos atmosféricos (Fernández-Jalvo y Andrews 2003; Kaufmann et al. 2011). Es entonces probable que los especímenes de aves se hallaran relativamente frescos al momento de ser desplazados por la marea y redepositados en las playas. Asimismo, los bajos niveles de abrasión podrían ser indicativos de eventos de transporte relativamente cortos en el tiempo, lo que implica cierta cercanía entre el lugar de acumulación de las osamentas y las playas a las que fueron transportados (zonas de acumulación). El mayor número de especímenes articulados, carcasas y elementos con tejido blando también da cuenta de estos escenarios, incluso sugiere que algunas osamentas no fueron depositadas por el mar, sino que provienen de organismos que perecieron in situ. Este supuesto también puede respaldarse por la proporción relativamente equitativa entre especímenes cuyos bordes de fractura están abradidos y aquellos que no presentan este signo de rodamiento. Estos últimos pudieron dar cuenta de roturas de los huesos en el lugar y ausencia de un posterior transporte por mar; en cambio, si el borde de fractura se halla abradido indica que este proceso aconteció con posterioridad a la fractura (Fernández-Jalvo y Andrews 2003). Por lo tanto, se plantea un origen mixto en la acumulación de los huesos de aves, tanto por arrastre marino como por animales que mueren en las playas y sus restos permanecen en el lugar de muerte o a corta distancia de este.

En el caso de los mamíferos, la disparidad en el grado de abrasión y la escasa presencia de concentraciones, huesos articulados y con presencia de tejido blando indican que en su mayoría habrían arribado al litoral como especímenes aislados. Como se observa en las figuras 5 y 6 , sus huesos tienden a alcanzar grados más altos de meteorización y abrasión que las aves. Esto puede ser consecuencia de un mayor tiempo de arrastre por el mar y/o que el período de exposición a la intemperie de los restos previo a su transporte hídrico haya sido suficiente para meteorizarlos (Fernández-Jalvo y Andrews 2003; Kaufmann et al. 2011), signos posteriormente borrados por los efectos de la acción hídrica. En efecto, los restos de mamíferos son precisamente los más abradidos, rasgo observado no solo en sus elementos completos, sino también en los bordes de fractura de aquellos huesos que no se hallaron enteros. Si bien no conocemos la velocidad del flujo del mar en la zona costera de bahía Moat, la predominancia de unidades anatómicas categorizadas dentro del grupo 3 (sensu Kaufmann et al. 2011) y la subrepresentación de mamíferos juveniles, sugiere que estos especímenes pudieron ser sometidos a contextos hídricos de alto flujo energético (quizá por eventos de tormenta). El origen (lugar de procedencia) de estas dispersiones observadas en los mamíferos es aún incierto, pero la diversidad en los grados de abrasión sugiere que las camadas de huesos provendrían de enclaves ubicados a distancias variables. En este punto es necesario considerar el espacio donde los guanacos y el ganado suelen llevar a cabo su accionar 
dentro del ámbito costero, dado que esto podría dar pistas sobre el lugar de procedencia de sus huesos acumulados en el intermareal. Si bien estos mamíferos pueden ser avistados en la zona de playas, su radio de acción tiende a permanecer en valles y espacios abiertos con pastizales, los cuales constituyen mejores lugares para pastar. Sin embargo, en invierno las nevadas impactan sobre el sustrato herbáceo y los animales se desplazan hacia el bosque y las zonas más bajas en busca de refugio y cobertura térmica. Para los guanacos, el estrés invernal y la inanición son, de hecho, las principales causas de muerte (Raedeke 1978: tabla 1; Estévez Escalera y Mameli 2000; Borrero 2007). Existen registros para la costa sur de Tierra del Fuego que relatan eventos de crudos inviernos que generaron contextos de mortandad en masa donde las carcasas de camélidos y ovejas fueron halladas en las playas y en sus bosques lindantes (Estévez Escalera y Mameli 2000). Con posterioridad a las muertes, distintos agentes y procesos desencadenan situaciones de dispersión de sus restos óseos que pueden concluir en el patrón de acumulación actualmente observado en intermareal. Por ejemplo, sus huesos pudieron quedar depositados en la costa luego de ser arrastrados desde el interior por medio de arroyos o ríos que desaguan en el mar (figura 1), removidos por los eventos de tormenta que sustraen las carcasas que yacen en las playas o en las cercanías de éstas, o bien sustraídos por los carnívoros cuyos rastros han dejado improntas en algunos especímenes (Estévez Escalera y Mameli 2000). Como indicamos anteriormente, las huellas dejadas por los carnívoros en conjunto con la abrasión, dispersión y desarticulación que exhiben los huesos de mamíferos, sugieren que la acción de estos agentes aconteció con anterioridad al transporte por mar y que luego el flujo hídrico depositó los restos óseos en el intermareal.

Entre las especies faunísticas más comunes en el registro arqueológico, se destacan diferencias observadas en las frecuencias de las unidades anatómicas naturalmente depositadas en las costas (tabla 2). En los conjuntos tafonómicos de pinnípedos predomina la región axial, particularmente las vértebras, aunque los radios y los metapodios también son abundantes. En cambio, en los guanacos prevalece la zona apendicular. Los restos de aves están representados por unidades anatómicas más variables y solo se encuentran ausentes o en escasas proporciones los especímenes pequeños o con muy baja densidad ósea. A diferencia de los mamíferos, esta diversidad y mayor completitud anatómica posiblemente esté relacionada con el origen y trayectoria de las carcasas arriba mencionado. En términos arqueológicos, estas diferencias en los perfiles esqueletarios que observamos en mamíferos y aves genera acumulaciones similares a las abundancias anatómicas que se espera hallar en los depósitos arqueofaunísticos de la zona (Alunni et al. 2020). En efecto, los esqueletos de aves suelen estar más completos que los mamíferos, mientras estos últimos tienen patrones más selectivos que usualmente se relacionan con decisiones económicas de transporte llevadas a cabo por los cazadores-recolectores. Esto nos alerta sobre la necesidad de efectuar análisis exhaustivos sobre los atributos tafonómicos de los especímenes arqueológicos como, por ejemplo, examinar si poseen algún grado de abrasión o si los huesos de aves fueron hallados en posición articulada durante la excavación. Asimismo, sería de utilidad examinar si los bordes de fractura hallados presentan algún grado de brillo o rodamiento, lo que podría ser informativo de situaciones de transporte y de contextos alóctonos en los cuales se produjo dicha fractura. Si bien no existen dudas sobre el origen antrópico de los concheros en el canal Beagle, los huesos naturalmente depositados generan conjuntos que, si alcanzan superficies estables que coinciden con la ubicación de sitios arqueológicos, pueden migrar al depósito e incorporarse en su matriz estratigráfica (Borrero 2007; Alunni et al. 2017). Esto podría afectar la representación de ciertos taxones y sus huesos, ya sea con su sobrerrepresentación o subrepresentación. Esta situación podría acentuarse en otros tipos de depósitos que no provengan de concheros, en donde las acumulaciones naturales pueden simular eventos de descarte bajo contextos de ocupaciones humanas. 


\section{CONCLUSIONES}

Las observaciones actualistas desarrolladas en bahía Moat muestran que la dinámica del intermareal podría actuar de manera disímil en la formación de los sitios arqueológicos y que dichos procesos impactarían en diferentes grados según su ubicación y la geoforma costera en la cual se emplacen. Por un lado, las entrantes de las bahías son más propensas a la acumulación de restos que los tramos centrales y las playas con contornos convexos. Es factible que aquí los eventos de acumulación se vean obstaculizados por una mayor incidencia de la energía hídrica y, por lo tanto, podría tratarse de sectores con efectos más abrasivos y destructivos sobre los sitios arqueológicos. En cambio, las entrantes estarían más afectadas por el arribo de materiales, lo que conlleva un incremento en la posibilidad de migraciones de restos óseos hacia los depósitos. Por otro lado, los efectos del oleaje alcanzan a los sitios ubicados en el supramareal y, posiblemente también, a aquellos localizados sobre antiguos cordones litorales. Al respecto, y considerando los eventos de avance y retroceso del mar acontecidos durante el Holoceno, es esperable que los mismos procesos que actualmente impactan sobre la integridad de los sitios costeros hayan afectado de igual manera a los yacimientos ubicados sobre las antiguas geoformas litorales durante los episodios transgresivos-regresivos. Estos procesos tafonómicos podrían generar discontinuidades o vacíos de información arqueológica (Zangrando 2018).

Los resultados de las observaciones actualistas realizadas en Moat han permitido reconocer distintas trayectorias para las aves y los mamíferos en general (marinos y terrestres) a través del análisis de los efectos tafonómicos. Estos patrones de preservación diferenciales constituyen marcos de referencia para el estudio de los sitios arqueológicos desde una perspectiva tafonómica. En el futuro, el análisis comparativo permitirá discutir la integridad de los sitios arqueológicos y, posiblemente, el origen de estos depósitos (acumulaciones naturales/culturales).

Por último, a partir de este trabajo identificamos tendencias en la distribución natural de restos óseos que permiten predecir la interacción entre las acumulaciones modernas y los sitios arqueológicos a partir de las características ambientales y geomorfológicas de la costa de bahía Moat. Un porcentaje significativo de depósitos arqueológicos ha estado expuesto a la incorporación natural de huesos durante el Holoceno tardío. Por esta razón, resulta esencial un abordaje tafonómico que contemple la representación de partes esqueletarias, la distribución y frecuencia de efectos tafonómicos y las características geomorfológicas de los contextos de depositación. La acción hídrica juega un rol fundamental en la acumulación y dispersión de restos óseos en bahía Moat. Los resultados de este abordaje tafonómico permiten predecir el grado de integridad de los sitios ubicados en los contextos ambientales aquí estudiados y constituyen herramientas valiosas para tomar decisiones en el marco de proyectos arqueológicos regionales.

\section{AGRADECIMIENTOS}

Estas investigaciones son financiadas por el proyecto PICT 2017-1230 (Dr. Zangrando) y PICT 2018-686 (Dra. Gutiérrez). A Alejandro Montes por su orientación sobre geomorfología costera. Agradecemos a Pablo Fernández y otro/a evaluador/a anónimo/a por las sugerencias que han permitido mejorar el contenido del manuscrito. Por último, queremos agradecer a Snipe S.A., Alejandro Patiño y Alejandro Winograd por proporcionarnos alojamiento y ofrecernos ayuda constante durante las actividades en el campo en Estancia Moat. 


\section{NOTAS}

1 "Los drumlins son colinas bajas, de forma dómica, alineadas con sus ejes mayores en forma paralela o subparalela, que se forman por debajo de hielo glacial en movimiento" (Ercolano et al. 2004).

\section{REFERENCIAS BIBLIOGRÁFICAS}

Alunni, D. V., M. A. Gutiérrez y A. F. Zangrando (2017). Natural accumulation and distribution of guanaco bones in the southernmost tip of Tierra del Fuego (Argentina): taphonomic analysis and archaeological implications. Journal of Taphonomy 15(1-3): 59-76.

Alunni, D. V., A. M Tivoli y A. F. Zangrando (2020). Movilidad y explotación de recursos terrestres por cazadores-recolectores costeros de Bahía Moat, costa sureste de Tierra del Fuego, Argentina. Latin American Antiquity 31(3): 576-594.

Alunni, D. V. y A. F. Zangrando (2012). Primeros datos sobre el transporte, procesamiento y consumo de guanacos en la localidad arqueológica Heshkaia (sudeste de Tierra del Fuego, Argentina). Magallania 40 (1): 319-331.

Andrade, B., P. Elizalde y M. Halaby (2004). Morfología de acantilados y plataformas litorales en la costa

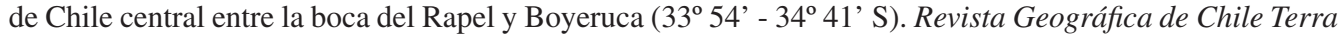
Australis 49: 299-311.

Arche, A. (2010). Sedimentología: del proceso físico a la cuenca sedimentaria. Madrid, Editorial CSICCSIC Press.

Bastida, R. y D. Rodríguez (2003). Mamíferos marinos de Patagonia y Antártida. Buenos Aires, Vázquez Mazzini.

Bayón, M. C. y G. Politis (2014). The inter-tidal zone Site of La Olla: early-Middle Holocene human adaptation on the Pampean coast of Argentina. En A. M. Evans y J. Flatman (eds.), Prehistoric Archaeology on the continental shelf: 115-130. Nueva York, Springer.

Behrensmeyer, A. K. (1978). Taphonomic and ecologic information from bone weathering. Paleobiology 4(2): 150-162.

Behrensmeyer, A. K., C. T. Stayton y R. E. Chapman (2003). Taphonomy and ecology of modern avifaunal remains from Amboseli Park, Kenya. Paleobiology 29(1): 52-70.

Bird, E. C. (2011). Coastal Geomorphology: An Introduction. Reino Unido, John Wiley \& Sons.

Bjerck, H. B., H. M. Breivik, E. L. Piana y A. F. Zangrando (2016). Exploring the role of pinnipeds in the human colonization of the seascapes of Patagonia and Scandinavia. En H. B. Bjerck, H. Breivik Mjelva, S. E. Fretheim, E. L. Piana, B. Skar, A. M. Tivoli y A. F. Zangrando (eds.), Marine Ventures: Archaeological Perspectives on Human-Sea Relations:51-71. Sheffield, Equinox.

Binford, L. R. (1981). Bones: Ancient Men and Modern Myths. Nueva York, Academic Press.

Borromei, A. M., J. F. Ponce, A. Coronato, M. S. Candel, D. Olivera y M. Okuda (2014). Reconstrucción de la vegetación posglacial y su relación con el ascenso relativo del nivel del mar en el extremo este del canal Beagle, Tierra del Fuego, Argentina. Andean Geology 41(2): 362-379.

Borella, F. (2004). Tafonomía regional y estudios arqueofaunísticos de cetáceos en Tierra del Fuego y Patagonia meridional. Oxford, British Archaeological Reports. 
Borella, F. y C. Favier Dubois (1994-95). Observaciones tafonómicas en la Bahía San Sebastián, costa norte de Tierra del Fuego, Argentina. Palimpsesto. Revista de Arqueología 4: 1-8.

Borella, F., M. A. Gutiérrez, H. R. Foderé y J. F. Merlo (2007). Estudio de densidad mineral ósea para dos especies de otáridos frecuentes en el registro arqueofaunístico patagónico (Otaria flavescens y Arctocephalus australis). En F. A. Morello, F, A. Prieto, M. Martinic y G. Bahamonde (eds.), Arqueología de Fuego-Patagonia. Levantando Piedras, Desenterrando Huesos y Develando Arcanos: 421-426. Punta Arenas, Ediciones CEQUA.

Borella, F. y S. Muñoz (2006). Observaciones tafonómicas sobre restos de pinnípedos en la costa norte fueguina (Argentina). Intersecciones en Antropología 7: 399-403.

Borrero, L. A. (2007). Longitudinal taphonomic studies in Tierra del Fuego, Argentina. En M. A. Gutiérrez, L. Miotti, G. Barrientos, G. Mengoni Goñalons y M. Salemme (eds.), Taphonomy and Zooarchaeology in Argentina: 219-233. International Series 1601. Oxford, Archaeopress.

Borrero, L. A. (2014). Multi-service taphonomy. Shells, garbage, and floating palimpsests. Intersecciones en Antropología. Volumen Especial 1: 13-20.

Bujalesky, G., S. Aliotta y F. Isla (2004). Facies del subfondo del canal Beagle, Tierra del Fuego. Revista de la Asociación Geológica Argentina 59(1): 29-37.

Corbat, M., A. M. Tivoli y A. F. Zangrando (2020). Aprovisionamiento de peces en el extremo oriental del canal Beagle (Tierra del Fuego, Argentina): una evaluación a partir del registro zooarqueológico de Bahía Moat. Archaeofauna 29: 41-57.

Cruz, I. (2008). Avian and mammalian bone taphonomy in southern continental Patagonia: a comparative approach. Quaternary International 180(1): 30-37.

Cruz, I., B. Ercolano, D. Cañete, M. S. Caracotche y C. Lemaire (2015). Tafonomía y procesos de formación en P96 (Punta Entrada, Santa Cruz, Argentina). Cuadernos del Instituto Nacional de Antropología y Pensamiento Latinoamericano 24(1): 96-115.

Elkin, D. C. (1995). Volume Density of South American camelid skeletal parts. International Journal of Osteoarchaeology 5: 29-37.

Ercolano, B., E. Mazzoni, M. Vázquez y J. Rabassa, J. (2004). Drumlins y formas drumlinoides del Pleistoceno inferior en Patagonia Austral, Provincia de Santa Cruz. Revista de la Asociación Geológica Argentina 59(4): 771-777.

Estévez Escalera, J. y L. Mameli (2000). Muerte en el canal: experiencias bioestratigráficas controladas sobre la acción sustractiva de cánidos. Archaeofauna (9): 7-16.

Fernández-Jalvo, Y. y P. Andrews (2003). Experimental Effects of Water Abrasion on Bone Fragments. Journal of Taphonomy 1(3): 147-163.

Forcelli, D. O. (2000). Moluscos magallánicos: guía de los moluscos de la Patagonia y del sur de Chile. Buenos Aires, Vázquez Mazzini.

Frangi, J. L., M. D. Barrera, J. Puigdefábregas, P. F. Yapura, A. M. Arambarri y L. Richter (2004). Ecología de los bosques de Tierra del Fuego. Ecología y Manejo de los Bosques de Argentina. La Plata, Editorial de la Universidad Nacional de La Plata.

Grosso, M., M. Trassens, C. Murray y R. Bastida (2019). Aportes para una caracterización de los ambientes 
intermareales y su aplicación en el estudio del registro arqueológico en el litoral marítimo argentino. Cuadernos del Instituto Nacional de Antropología y Pensamiento Latinoamericano 28(1): 17-35

Gutiérrez, M. A. y C. Kaufmann (2007). Criteria for the identification of formation processes in guanaco (Lama guanicoe) bone assemblages in fluvial-lacustrine environments. Journal of Taphonomy 5(4)1:151-176.

Gutiérrez, M. A., C. A. Kaufmann, M. E. González, N.A. Scheifler, D. J. Rafuse, A. Massigoge y M. C. Álvarez (2016). The role of small carnivores in the movement of bones: implications for the Pampas archaeofaunal record, Argentina. Archaeological and Anthropological Sciences 8(2): 257-276.

Isla, F. I., G. G. Bujalesky y A. Coronato (1999). Procesos estuarinos en el canal Beagle, Tierra del Fuego. Revista de la Asociación Geológica Argentina 54(4): 307-318.

Iturraspe, R. y C. Schroeder (2015). El clima en el Canal Beagle. En L. A. Orquera y E. L. Piana (eds.), La vida material y social de los Yamana: 36-44. Buenos Aires, Eudeba-Instituto Fueguino de Investigaciones Científicas-IFIC.

Kaufmann, C. A., M. A. Gutiérrez, M. C. Álvarez, M. E. González y A. Massigoge (2011). Fluvial dispersal potential of guanaco bones (Lama guanicoe) under controlled experimental conditions: the influence of age classes to the hydrodynamic behavior. Journal of Archaeological Science 38(2): 334-344.

Klein, R. G. y K. Cruz-Uribe (1984). The Analysis of Animal Bones from Archaeological Sites. Chicago, The University of Chicago Press.

Lloris, D. y J. Rucabado (1991). Ictiofauna del Canal Beagle (Tierra del Fuego), aspectos ecológicos y análisis biogeográfico. Madrid, Instituto Español de Oceanografía (Publicación Especial 8).

Martínez, C. (2001). El efecto ensenada en los procesos litorales de las ensenadas de Valparaíso, Algarrobo y Cartagena, Chile Central. Tesis para optar al grado de Magíster en Geografía. Chile, Universidad de Chile, Facultad de Arquitectura y Urbanismo.

Massigoge, A., D. J. Rafuse, M. C. Álvarez, M. E. González, M. A. Gutiérrez, C. A. Kaufmann y N.A. Scheifler (2015). Beached penguins on the Atlantic Coast in the Pampas region of Argentina: Taphonomic analysis and implications for the archaeological record. Palaeogeography, Palaeoclimatology, Palaeoecology 436: 85-95.

Muñoz, S, C. Cruz y D. Daniela Cañete Mastrángelo (2016). Humanos y lobos marinos al sur del río Santa Cruz durante el Holoceno: múltiples líneas de evidencia para el estudio de las relaciones interespecíficas. En F. Mena (ed), Arqueología de la Patagonia: de mar a mar: 299-309. Santiago de Chile, Ediciones CIEP.

Orquera, L. A. y E. L. Piana (1991). La formación de montículos arqueológicos en la región del canal Beagle. Runa XIX (1989-1990): 59-82.

Orquera, L. A. y E. L. Piana (1999). Arqueología de la región del canal Beagle (Tierra del Fuego, República Argentina). Buenos Aires, Sociedad Argentina de Antropología.

Rabassa, J., A. Coronato, G. G. Bujalesky, M. Salemme, C. Roig, A. Meglioli, C. Heusser, S. Gordillo, F. Roig Juñento, A. Borromei y M. Quattrocchio (2000). Quaternary of Tierra del Fuego, southernmost South America: an updated review. Quaternary International 68: 217-240.

Raedeke, K. (1978). El guanaco de Magallanes. Chile. Su distribución y biología. CONAF Publicación Técnica $\mathrm{N}^{\circ} 4.182$ pp.

Rick, T. C., J. M. Erlandson y R. L. Vellanoweth (2006). Taphonomy and Site Formation on California's Channel Islands. Geoarchaeology. An International Journal 21(6): 567-589. 
Schiavini, A. y P. Yorio (1995). Distribution and abundance of seabird colonies in the Argentine sector of the Beagle Channel, Tierra del Fuego. Marine Ornithology 23: 39-46.

Zangrando, A. F. (2009). Historia evolutiva y subsistencia de cazadores-recolectores marítimos de Tierra del Fuego. Buenos Aires, Sociedad Argentina de Antropología.

Zangrando, A. F. (2010). Coastal archaeology and hunter-gatherers in the south-eastern of Tierra del Fuego. Journal of Island and Coastal Archaeology 5(2): 288-291.

Zangrando, A. F. (2018). Poblamiento temprano y arqueología de costas en Patagonia y Tierra del Fuego: vacío de información, preconceptos y perspectivas. Intersecciones en Antropología 19(2): 63-97.

Zangrando A. F., D. V. Alunni, M. P. Martinoli, A. M. Tivoli y E. L. Piana (2010). Arqueología de la región de Moat (Tierra del Fuego, Argentina): estudios preliminares en la localidad arqueológica Heshkaia. En J. R. Bárcena y H. Chiavazza (eds.), Arqueología Argentina en el Bicentenario de la Revolución de Mayo, Actas XVII Congreso Nacional de Arqueología Argentina: 2005-2010. Mendoza, Universidad Nacional de Cuyo.

Zangrando, A. F., J. F. Ponce, M. P. Martinoli, A. Montes, E. Piana y F. Vanella (2016). Paleogeographic changes drove prehistoric fishing practices in the Cambaceres Bay (Tierra del Fuego, Argentina) during the middle and late Holocene. Environmental Archaeology: The Journal of Human Paleoecology: 1-11. http:// dx.doi.org/10.1080/14614103.2015.1130888

Zangrando, A. F., A. M. Tivoli, J. F. Ponce, D. V. Alunni, M. C. Fernández Ropero y M. P. Martinoli (2021). Colonización humana de Tierra del Fuego: Contextos arqueológicos pre-trangresivos en la costa norte del Canal Beagle. Chugara Revista de Antropología Chilena. En prensa. 